\title{
A study for evaluation of two protocols comprising of clomiphene citrate, human menopausal gonadotropin with or without follicle stimulating hormone for ovulation induction in patients with infertility for intrauterine insemination
}

\section{Ashok Verma*, Shivani Sharma, Suresh Verma, Pankaj Sharma, Tenzin Tsamo Tenga, Indu Chauhan}

Department of Obstetrics and Gynecology, Dr. Rajendra Prasad Government Medical College Kangra at Tanda, Himachal Pradesh, India

Received: 14 April 2019

Accepted: 14 May 2019

*Correspondence:

Dr. Ashok Verma,

E-mail: dr.ashok_verma@yahoo.com

Copyright: () the author(s), publisher and licensee Medip Academy. This is an open-access article distributed under the terms of the Creative Commons Attribution Non-Commercial License, which permits unrestricted non-commercial use, distribution, and reproduction in any medium, provided the original work is properly cited.

\section{ABSTRACT}

Background: To compare two protocols comprising of FSH/CC/HMG and CC/HMG for ovulation induction and IUI in women with infertility.

Methods: 60 women with unexplained infertility were randomized using sequentially numbered opaque envelope method. Group A received inj FSH 150 units on day 2 of menstrual cycle and clomiphene citrate $100 \mathrm{mg}$ from day 3 7, followed by injection HMG 150 units on day 9 of menstrual cycle. Group B received clomiphene citrate $100 \mathrm{mg}$ from day 3-7, and HMG 150 units on day 7 and 9 of the menstrual cycle. Ovulation triggered with hCG 5000 units when dominant follicle was $18 \mathrm{~mm}$. Single IUI was done $36-42$ hours afterwards.

Results: Pregnancy occurred in 3 out of 30 women in 116 cycles Group A (with FSH) with a pregnancy rate of 10 percent, and $2.8 \%$ per cycle. In group B (without FSH) pregnancy occurred in 3 out of 30 women in 117 cycles with pregnancy rate of 10 percent, and $2.6 \%$ per cycle. The number of follicles per cycle was 1.36 and follicle size was $18.57 \mathrm{~mm}$ in group A. While in Group B numbers of follicles per cycle were 1.22, with average size of $18.9 \mathrm{~mm}$. Mean endometrial thickness was $7.7 \mathrm{~mm}$ in Group A and 6.37 in Group B ( $\mathrm{p}=.01$, significant). Mild OHSS was observed in one woman in Group B. No other side effects were observed in both the groups.

Conclusions: The controlled ovarian stimulation regimes used in this study are equally effective, easy to administer, require less intensive monitoring and fewer medications, with little risk of OHSS and multiple gestation.

Keywords: Clomiphene citrate, Follicle stimulating hormone, Intrauterine insemination, Unexplained infertility

\section{INTRODUCTION}

It is estimated that infertility affects 10 to $14 \%$ of the Indian population. Prevalence of infertility in couples actively attempting to conceive varies from $13.9 \%$ in Africa, $12.5 \%$ in China, $12.5 \%$ in India, $10.7 \%$ in UK to $7.2 \%$ in USA. India faces a high burden of infertility, with 22 to 33 million reproductive age couples suffering from lifetime infertility. Female factor accounts for $40 \%-$ $50 \%$ of infertility, while male factor, which is on the rise in India, accounts for $30 \%$ to $40 \%$. Assuming the marital rate in 2020 is similar to the current rate, the number of infertile couples could increase from 220 million in 2015 to 244 million by $2020 .^{1}$ 
Human beings are remarkably fertile. Most women are capable of conceiving within two years of trying. However infertility has been reported since ancient times and is a common human burden. It has been established that factors contributing to infertility include both male and female factors such as increasing rates of ovulatory failures, tubal blockage and conditions such as endometriosis. Additionally, when the pregnancy is delayed to an older age when couples become less fecund also contributes to infertility. ${ }^{2}$ The World Health Organization has listed infertility as a global public health issue. According to WHO, the major millennium development challenge will be to make management of infertility more accessible to the estimated 80 million couples who are unable to conceive. ${ }^{3}$

Most couples seeking infertility treatment are subfertile, with a decreased monthly conception rate, but natural pregnancy is possible. Approximately $25 \%$ of infertile women have problems with ovulation. These include inability to produce fully matured eggs or failure to ovulate. Out of all infertility cases, $30 \%$ are unexplained. ${ }^{4}$

Intrauterine insemination has demonstrated increased pregnancy rates in sub-fertile men when compared to timed intercourse in both natural ovulation and ovulation induction cycles. $^{5}$ Intrauterine insemination with ovulation induction has also demonstrated increased live birth rates in unexplained infertility when compared with timed intercourse and ovulation induction. ${ }^{6}$ Intrauterine insemination (IUI) with husband's semen is the first line technique for many conditions of infertility including unexplained infertility and minimal or mild endometriosis. Several studies have demonstrated that IUI with controlled ovarian stimulation (COS) is better than IUI alone. ${ }^{7}$

Compared with natural cycle of IUI, ovarian stimulation may improve the treatment outcome of couples with unexplained infertility. ${ }^{8}$ However, significant risks of ovarian hyperstimulation syndrome (OHSS) and multiple pregnancies remain. In addition there is small but finite risk of infection following IUI. Infertility still continues to pose a great problem in India including the state of Himachal Pradesh.

The present study is an attempt to fill the gap wherein an effort has been made to identify in detail the variables that contribute to the success of CC/HMG/IUI and $\mathrm{CC} / \mathrm{HMG}+\mathrm{FSH} / \mathrm{IUI}$ treatments.

Objective of this study was to compare two protocols comprising of $\mathrm{FSH} / \mathrm{CC} / \mathrm{HMG}$ and $\mathrm{CC} / \mathrm{HMG}$ for ovulation induction and IUI in women with infertility.

\section{METHODS}

After approval of the "Institutional Ethics Committee", the study was conducted for a period of one year with effect from June 2016 to May 2017 in the Department of
Obstetrics and Gynecology, in association with the Department of Radio-diagnosis, at Dr Rajendra Prasad Government Medical College at Tanda, District Kangra H.P.

The couples attending the infertility clinic suffering either from primary or secondary infertility, and consenting to participate in the study were enrolled.

\section{Inclusion criteria}

Women between 18 to 40 years age attending infertility clinic with

- At least one patent fallopian tube on hysterosalpingography

- Regular menstrual cycles

- Normal TSH and Prolactin levels

- Normospermic male partner as per WHO guidelines as under:

- Liquefaction- complete in $60 \mathrm{~min}$

- Volume- $1.5 \mathrm{~mL}$

- Color- Opalescent white

- Concentration (mL)- 15 million

- Progressive motility- $32 \%$

- Vitality $-58 \%$

- Morphology- $4 \%$

- Leukocytes (mL)- <1 million.

\section{Exclusion criteria}

- Women with untreated endocrinological disorders in the form of thyroid dysfunction, hyperprolactinemia, cushings syndrome, and uncontrolled diabetes mellitus

- Couples not willing to participate in the study.

Preliminary workup included demographic profile; age, occupation, education, socio-economic status, history of infertility; primary or secondary infertility, duration of infertility, history of previous treatment. Menstrual history, obstetric history, sexual history, past historyhypertension, diabetes, thyroid dysfunction, renal disease, and sexually transmitted disease was also noted. Investigations included semen analysis, hormonal evaluation (serum TSH and day 2 serum prolactin), ultrasound (USG) of the pelvis, hysterosalpingogram, and laproscopy if indicated. A total of 60 women with unexplained infertility were recruited in the study. These women were than randomized into two groups using sequentially numbered opaque envelope method (SNOSE). They then received either of the two controlled ovarian stimulation regimes as under:

Group A: Injection of purified urinary follicle stimulating hormone (FSH) 150 IU was administered intramuscularly on day two of last menstrual period and clomiphene citrate (CC) 100mg was given for 5 days (day 3-7) followed by intramuscular administration of human 
menopausal gonadotropin (HMG) of 150 IU on day nine of last menstrual period.

Group B: Women were given clomiphene citrate (CC) $100 \mathrm{mg}$ from day 3 to day 7, and human menopausal gonadotropin (HMG) 150 IU intramuscularly on day 7 and 9 from last menstrual period.

In both the groups, follicle monitoring was started using trans-vaginal ultrasound (TVS) from day 11 till the dominant follicle was $18-20 \mathrm{~mm}$. Then, ovulation was triggered by human chorionic gonadotropin (hCG) injection of 5000 IU. IUI was done 36 to 42 hours after ward. Luteal phase support was given in the form of oral or vaginal micronized progesterone $300 \mathrm{mg}$ per day. A maximum of four cycles were tried. The primary outcome was to observe the pregnancy rate in two protocols proposed in the study.

\section{Statistical analysis}

Sample size was studied before the start of the study. Means, standard deviations, medians and ranges were calculated for descriptive purposes. Comparisons of patient characteristics, response to stimulation regimes, pregnancy rates per cycle, average number of follicles per cycle and average follicle size per cycle were done using chi-square test and student t-test. $\mathrm{P}$ values less than .05 were considered statistically significant.

\section{RESULTS}

The study comprised 60 women with unexplained infertility that underwent 233 cycles of controlled ovarian stimulation and IUI. The demographic characteristics, BMI and endocrinologic characteristics are shown in Table 1 and were similar in both the groups.

Table 1: Demographic characteristics/ baseline characteristics of the patients with infertility in both the groups.

\begin{tabular}{|llll|}
\hline Parameter & Group A & Group B & P value \\
\hline Age (mean) years & $30.36 \pm 3.2$ & $29.86 \pm 3.9$ & .42 \\
\hline Duration of infertility (Range in Years) & $6.8 \pm 3.1(2-15)$ & $5.2 \pm 3.5(1-18)$ & .62 \\
\hline Socio-economic status & & & \\
\hline Low socio-economic status & $13(43.3 \%)$ & $19(63.3)$ & \\
\hline Middle socio-economic status & $17(56.6 \%)$ & $11(36.6)$ & \\
\hline Address & & & \\
\hline Urban & $17(56.6)$ & $19(63.3)$ & \\
\hline Rural & $13(43.3)$ & $11(36.6)$ & .83 \\
\hline BMI $\left(\mathrm{Kg} / \mathrm{m}^{2}\right.$, Range) & $22.2 \pm 4.6(17-30)$ & $22.3 \pm 3.2(18-31)$ & .88 \\
\hline TSH (mIU/L) & 2.26 & 3 & .89 \\
\hline Prolactin (ng/dL) & 14.05 & 14.05 & .98 \\
\hline RBS $(\mathrm{mg} / \mathrm{dL})$ & 96.6 & 95.3 & \\
\hline
\end{tabular}

Table 2: Comparison of ovulation induction cycles.

\begin{tabular}{|lll|}
\hline Parameters & Group A & Group B \\
\hline Number of induction cycles & 116 & 117 \\
\hline Cycles with ovulation & 110 & 113 \\
\hline Total number of dominant follicles & 150 & 138 \\
\hline Cycles cancelled & 9 & 4 \\
\hline Number of cycles of IUI given & 107 & 113 \\
\hline Cancellation rate per induction cycle (Per cent) & 7.75 & 3.41 \\
\hline Ovulation rate per cycle (Per cent) & 94.82 & 96.58 \\
\hline
\end{tabular}

Table 3: Endometrial thickness.

\begin{tabular}{|lllll|}
\hline \multirow{2}{*}{ Endometrial thickness $(\mathrm{mm})$} & Group A & & Group B & Per cent \\
\hline$<6 \mathrm{~mm}$ & Number & Per cent & Number & 40 \\
\hline $6-10 \mathrm{~mm}$ & 10 & 33.33 & 12 & 56.66 \\
\hline$>10 \mathrm{~mm}$ & 14 & 46.66 & 17 & 3.33 \\
\hline Total & 6 & 20 & 30 & 100 \\
\hline
\end{tabular}

Mean: Group A: 7.71 \pm 2.1 , Group B: 6.37 $\pm 2.2(\mathrm{p}=.0185)$ 
As shown in Table 2, 30 women were recruited in group $\mathrm{A}$ and underwent 116 cycles of controlled ovarian hyperstimulation followed by IUI. In group B, 30 women underwent 117 cycles of controlled ovarian stimulation and IUI. Nine cycles in group A and four cycles in Group B were cancelled due to refusal of patient or lost to follow up. Cancellation rate per induction cycle was 7.75 percent in Group A and 3.41 percent in group B.
Ovulation rate per cycle was 94.82 percent in group A and 96.58 percent in Group B. Pregnancy rate was 10 percent in each group.

The mean endometrial thickness was $7.71 \pm 2.1 \mathrm{~mm}$ in Group A and 6.37 $\pm 2.2 \mathrm{~mm}$ in Group B and the difference was statistically significant $(\mathrm{p}=.0185)$ as shown in Table 3.

Table 4: Comparison of result for pregnancy rate per cycle, mean E.T, mean number of follicles per cycle and mean size of follicles.

\begin{tabular}{|lllll|}
\hline Outcomes & Group A & Group B & T test & P value \\
\hline Pregnancy rate per cycle (Per cent) & 2.80 & 2.67 & & 0.5 \\
\hline Mean ET $(\mathrm{mm})$ & 7.71 & 6.37 & 2.1352 & 0.0185 \\
\hline Average number of follicles per cycle & 1.36 & 1.22 & 1.4918 & 0.0706 \\
\hline Average follicle size $(\mathrm{mm})$ & 18.57 & 18.97 & -1.0045 & 0.1597 \\
\hline
\end{tabular}

Table 5: Life table analysis.

\begin{tabular}{|c|c|c|c|c|c|c|c|c|}
\hline \multirow[t]{2}{*}{ Cycle } & \multicolumn{2}{|c|}{$\begin{array}{l}\text { No. of couples in } \\
\text { different cycles }\end{array}$} & \multicolumn{2}{|c|}{$\begin{array}{l}\text { Pregnancy during } \\
\text { cycles }\end{array}$} & \multicolumn{2}{|c|}{ Drop out cancellation } & \multicolumn{2}{|c|}{$\begin{array}{l}\text { Pregnancy rate per cycle } \\
\text { of IUI (Per cent) }\end{array}$} \\
\hline & Group A & Group B & Group A & Group B & Group A & Group B & Group A & Group B \\
\hline 1 & 30 & 30 & - & - & 2 & - & - & - \\
\hline 2 & 30 & 30 & 2 & 1 & 4 & -- & 7.6 & 3.3 \\
\hline 3 & 28 & 29 & - & 1 & 3 & 1 & - & 3.5 \\
\hline 4 & 28 & 28 & 1 & 1 & - & 3 & 3.5 & 4 \\
\hline Total & 116 & 117 & 3 & 3 & 9 & 4 & 2.8 & 2.65 \\
\hline
\end{tabular}

As shown in Table 4, pregnancy rate per cycle were 2.8 percent and 2.67 percent in Group A and B respectively and were similar. The average number of follicles obtained per cycle in Group A was 1.36 and in Group B it was $1.22(p=.07)$ while the average size of follicle in Group A was $18.57 \mathrm{~mm}$ and in Group B was $18.97 \mathrm{~mm}$ and was not significant $(\mathrm{p}=0.15)$.

None of the regimes resulted in higher order gestation. Mild ovarian hyperstimulation (OHSS) was reported in one woman $(3.3 \%)$ in Group B while none developed OHSS in Group A.

Life table analysis is shown in Table 5. Total number of induction cycles given in group A were 116 and in group $B$ were 117 . Out of these 107 IUI cycles were done in group A whereas 113 were done in group B. Pregnancy rate of $2.8 \%(n=3)$ per IUI cycle was observed in group A whereas a pregnancy rate of $2.65 \%(n=3)$ per IUI cycle was observed in group B.

\section{DISCUSSION}

The use of ovulation induction combined with IUI as a treatment for sub fertility in women with patent fallopian tubes has increased in recent years and in fact remains a mainstay of fertility therapy. The reported pregnancy rates per cycle have usually varied between $8 \%$ and $22 \%$, but very low (4\%) and high $(40 \%)$ pregnancy rates have also been reported. ${ }^{9}$

However, ovulation induction and IUI facility is not available to most of the population in rural areas like ours in low resource settings. In one year period we could study only 60 couples with unexplained infertility. In the present study, 60 percent of women were from urban area, even though the hospital is in rural area suggesting that people from urban area have better access to avail hospital facilities like IUI that involve financial burden including drugs and transport cost. There were no statistically significant differences between the two groups in age, duration of infertility, BMI and endocrine status.

In the present study we have achieved a fairly good rate of ovulation i.e., 94.62 and 96.58 percent in group A and group B respectively. Pregnancy rate was $2.8 \%$ per cycle in group A and $2.65 \%$ per cycle in group B. In a similar study conducted by Romeu A et al, consisting of 364 patients and 416 ovulation induction cycles, $98.28 \%$ showed ovulation. ${ }^{7}$ Pregnancy rate per cycle was $17.31 \%$ and cancellation rate of $8.9 \%$. Further, Christin $\mathrm{S}$ et al 
made a study comprising of two groups: Group A (rFSH step-up) and Group B (rFSH step-down) having 44 and 39 patients in each group who were given 85 and 72 OI cycles and observed the ovulation rate of $70 \%$ and $61 \%$ in group A and group B respectively. ${ }^{10}$ In a study by Homberg R where clomiphene citrate and FSH were used for ovulation induction, an ovulation rate of $56.95 \%$ and a pregnancy rate of $14.35 \%$ were observed. ${ }^{11}$ Peripheral anti-estrogenic effects of CC might explain low pregnancy rates in our study and other similar studies.

In the present study, we have observed that the mean endometrial thickness was $7.71 \mathrm{~mm}$ in group $\mathrm{A}$ and $6.37 \mathrm{~mm}$ in group B and was statistically different. Average number of follicles in group A and group B stood at 1.36 and 1.22 respectively. Further, it was observed that the mean size of follicle was $18.57 \mathrm{~mm}$ and $18.97 \mathrm{~mm}$ in group A and group B respectively.

Turhan $\mathrm{N}$ et al, reported in their study that the mean ET was $8.2 \mathrm{~mm}$ to $8.3 \mathrm{~mm}$ while dominant follicle count was 1.4 to 1.5 in group $\mathrm{A}$ and group $\mathrm{B}$ when ovulation induction was done by clomiphene citrate. ${ }^{12}$ Similarly, ET was observed to be $8.1 \mathrm{~mm}$ and average number of follicle 2.2 in group treated with $\mathrm{CC}$ in a study conducted by Akbari $\mathrm{S}$ et al. ${ }^{13}$ Similar results were reported by Chaudhary K, and Gupta K on the women treated with $\mathrm{CC}+$ Gonadotropin and are in conformity with the results of our study. ${ }^{14,15}$

In the present study, $10 \%$ pregnancy rates were observed in both the groups where the ET was $6-10 \mathrm{~mm}$. In a study conducted by Nuojua $S$ et al, on 683 women, pregnancy rate per cycle was $12.7 \%$ when the ET was $6-10 \mathrm{~mm}$. Shoham et al, and Moradan S, demonstrated that no pregnancy occurs, if endometrium is $<7 \mathrm{~mm}$ in thickness. Endometrial thickness of $7-8 \mathrm{~mm}$ indicates endometrial maturity. ${ }^{16-18}$ The studies suggest that a triple line endometrium with a thickness $>7-8 \mathrm{~mm}$ is conducive to pregnancy.

Intrauterine insemination is a relatively simpler and less expensive. The pregnancy rate was $10 \%$ in each group in our study. Mukherjee $\mathrm{S}$ et al, reported that group $\mathrm{A}$ (uFSH $+\mathrm{CC}$ ) had PR of $11 \%$ compared to $6.3 \%$ of group $\mathrm{B}$ (CC alone) in couples with unexplained infertility. ${ }^{19}$ Gupta $\mathrm{K}$ et al, in their study observed higher pregnancy rate of $20 \%$ in $\mathrm{CC}+\mathrm{HMG}$ group as compared to pregnancy rate of $15 \%$ in letrozole group. ${ }^{15}$ In a similar study to the present study Chung MT et al, reported pregnancy rate of $14.8 \%$ in group $1(150 \mathrm{U} \mathrm{rFSH}+\mathrm{CC})$ as compared to $20.4 \%$ in group $2(100 \mathrm{U} \mathrm{rFSH}+\mathrm{CC}) .{ }^{20} \mathrm{In}$ another study, Goverde $\mathrm{AJ}$ et al, observed pregnancy rates of $7.4 \%$ and $8.7 \%$ in IUI alone and $\mathrm{COH}+\mathrm{IUI}$ groups respectively. ${ }^{21}$

In the present study only one case of mild OHSS in group B was observed which was managed as per protocol guidelines while none was present in group A. Van Santbrink EJ et al, Christin $\mathrm{S}$ et al, Balasch et al and
Hamilton et al have observed that OHSS ranged from 0$11 \%$ in their studies. $22-25$

In the present study, all the pregnancies occurred only in age group <35years in group A as well as group B.

In a retrospective analysis of the outcomes of 9, 963 consecutive IUI cycles, Stone BA et al, showed that the pregnancy rates were $18.9 \%, 13.9 \%, 12.4 \%, 11.4 \%, 4.7 \%$ and $0.5 \%$ in the age groups of $<26,26-30,31-35,36-40$, 41-45 and $>45$, respectively. ${ }^{26}$ In older couples, there may be a further compromise in fertility due to a higher rate of sperm aneuploidies. ${ }^{26}$ Brzechffa $\mathrm{P}$ et al, in a similar study reported $23.1 \%$ pregnancies in women below 35 years age. $^{27}$ Age has a negative impact on ovarian reserve, oocyte quality, and a higher probability of fibroids, tubal pathology and pelvic inflammatory disease.

\section{CONCLUSION}

The controlled ovarian stimulation regimes used in this study are equally effective, easy to administer, require less intensive monitoring and fewer medications, with little risk of OHSS and multiple gestation.

Funding: No funding sources

Conflict of interest: None declared

Ethical approval: The study was approved by the Institutional Ethics Committee

\section{REFERENCES}

1. Iyer M. The Times of India, New Delhi, Friday, July 14, 2017. Available at: https://timesofindia.indiatimes.com/2017/7/14/archiv elist/year-2017,month-7,starttime-42930.cms.

Accessed on 15 July 2017.

2. Gyaneshwar R, Raviraj P. Is the prevalence of infertility increasing? Insight into infertility management. 2012:1-5.

3. Vayena E, Rowe PJ, Griffin PD. Medical, ethical and social aspects of assisted reproduction. Current Practices and Controversies in Assisted Reproduction: report of WHO meeting, Geneva, Switzerland. 2001. Available at: academic.oup.com/humrep/article/19/1/3/690117. Accessed 15 April 2019.

4. Ganesh A, Goswami SK, Chattopadhya R, Chaudhury K, Chakravarty BN. Comparison of Letrozole with continuous gonadotrophins and comiphene-gonadotrophin combination for ovulation induction in1387 PCOS women after clomiphene citrate failure: a randomized prospective clinical trial. J Assisted Reprod Genet. 2009;26:19-24.

5. Mitwally MF, Casper RF. Use of aromatase inhibitor for induction of ovulation in patients with an inadequate response to clomiphene citrate. Fertil Steril. 2001;75:305-9.

6. Brzechffa PR, Daneshmand S, Buyalos RP. Sequential clomiphene citrate and human 
menopausal gonadotrophin with intrauterine insemination: the effect of patient age on clinical outcome. Hum Reprod. 1998;13(8):2110-4.

7. Romeu A, Monzo A, Peiro T, Diez E, Peinado A, Quintero A. Endogenous LH surge versus hCG as ovulation trigger after low dose highly purified FSH in IUI: A comparison of 761 cycles. J Assist Reprod Genet. 1997;14(9):518-24.

8. Gupta S, Tempe A, Sahu L. Supplementation with estradiol valerate and gonadotropins in clomiphene citrate stimulated IUI cycles. IJBAR. 2014;5(04):211-4.

9. Corsan G, Trias A, Trout S, Kemmann E. Ovulation induction combined with intrauterine insemination in women 40 years of age and older: is it worthwhile. Hum Reprod. 1996;11(5):1109-12.

10. Christin-Maitre S, Hugues JN. A comparative randomized multicentric study comparing the step up versus step down protocol in polycystic ovary syndrome. Hum Reprod. 2003;18(8):1626-31.

11. Homburg R. Clomiphene Citrate - the end of an era? A mini review. Hum Reprod. 2005;20:2043-51.

12. Turhan N, Pekel A, Onaran Y, Duvan ZCI, Bayrak O. Single or double sperm wash processing by density gradient centrifugation: Effect on clomiphene citrate induced intrauterine insemination cycle outcomes. Turk J Med Sci. 2011;41(1):39-44.

13. Akbari S, Roozbahani MA, Roozbahani FA. Comparing of letrozole versus clomiphene citrate combined with gonadotrophins in intrauterine insemination cycles. Iran J Reprod Med. 2012;10(1):29-31.

14. Chaudhary K, Suri V, Dhaliwal LK, Gainder S. Comparison of efficacy of letrozole and low dose gonadotrophins combination with clomiphene as a controlled ovarian stimulation regime prior to intrauterine insemination in patients with unexplained infertility. Fertil Sci Res. 2014;1(2):98103.

15. Gupta K, Das B. Comparative evaluation of sequential regimes of gonadotropins with clomiphene citrate and letrozole for ovulation induction. Int J Phar Res Heal Sci. 2015;3(2):585-91.

16. Nuojua S, Tomas C, Bloigu R, Tumivaara L, Martikainen $\mathrm{H}$. Intrautrine insemination treatment in subfertility: an analysis of factors affecting outcome. Hum Reprod. 1999;14(3):698-703.

17. Shoham Z, Carlo CD, Patel A, Conway GS, Jacobs HS.. Is it possible to run a successful ovulation program based on ultrasound monitoring / The importance of endometrial monitoring. Fertil Steril. 1991;56:836-41.

18. Moradan S. Assessment of the relationship between endometrial thickness and number of dominant follicles in pregnancy rate among 361 intrauterine insemination cases. J Sem Univer Med Sci. 2008;9(3):217-22.

19. Mukherjee S, Sharma S, Chakarvarty BN. Comparitive evaluation of pregnancy outcome in gonadotrophin-clomiphene combination vs clomiphene alone in polycystic ovarian syndrome and unexplained infertility: a prospective clinical trial. J Hum Reprod Sci. 2010;3(2):80-4.

20. Chung MT, Chan TF, Loo TC, Tang HH, Lin $1 Y$, Tsai YC. Comparison of the effect of two different doses of recombinant gonadotropin for ovarian stimulation on the outcome of intrauterine insemination. Taiwa J Obst Gynecol. 2011;50(1):5861.

21. Goverde AJ, McDonnell J, Vermeiden JP,Schats R, Rutten FFH, Schoemaker J. Intrauterine insemination or in vitro fertilization in idiopathic subfertility and male subfertility: A randomized trial and costeffectiveness analysis. Lancet. 2000;355:13-8.

22. Santbrink V, Fauser BC. Is there a future for ovulation induction in the current era of assisted reproduction? Hum Reprod. 2003;18(12):2499-502.

23. Christin-Maitre S, Hugues JN. A comparative randomized multicentric study comparing the step up versus step down protocol in polycystic ovary syndrome. Hum Reprod. 2003;18(8):1626-31.

24. Balasch J, Fabregues F, Creus M. Follicular development and hormone concentrations following rFSH administration for anovulation associated with polycystic ovarian syndrome: a prospective, randomized comparison between low dose step-up and modified step-down regimens. Hum Reprod. 2001;16:652-6.

25. Hamilton. Ovarian hyperstimulation syndrome. 1991;689-924.

26. Stone BA, Vargyas JM, Ringer GE, Stein AL, Marrs RP. Determinants of outcome of intrauterine insemination: analysis of outcomes of 9,963 consecutive cycles. Am J Obstet Gynaecol. 1999;180(6):1522-34.

27. Brzechffa PR, Daneshmand S, Buyalos R. Female and male partner age and menotrophin requirements influence pregnancy rates with human menopausal gonadotrophin therapy in combination with intrauterine insemination. Hum Reprod. 1997;12(1):29-33.

Cite this article as: Verma A, Sharma S, Verma S, Sharma P, Tenga TT, Chauhan I. A study for evaluation of two protocols comprising of clomiphene citrate, human menopausal gonadotropin with or without follicle stimulating hormone for ovulation induction in patients with infertility for intrauterine insemination. Int J Reprod Contracept Obstet Gynecol 2019;8:2487-92. 